\title{
Early Memories of Positive Emotions and its Relationships to Attachment Styles, Self-Compassion and Psycopathology in \\ Adolescence
}

\section{Marina Cunha', Maria Inês Martinho, Ana Xavier, \& Helena Espírito Santo}

Miguel Torga Superior Institute, Coimbra, Portugal

$\overline{\mathrm{M}}$

Cognitive-Behavioural Research Centre, University of Coimbra, Portugal

Fineicc

\section{Introduction}

Literature has shown that early childhood experiences, especially those related to feelings of warnth or safeness play a key role in emotional and social subsequent development. These early experiences of safeness and especially in face of setbacks or failures /Gilbert, 2005, Ritcher Gilbert \& especially in face of selbacks ory fallures (Cllbent, 2005; Richer, peEwan, 2009). Reseaich has shown thar seff-compassion is associated with 2003; Neff, Kirkpatrick, \& Rucle, 2007). Given the developmental tasks adolescence it may be beneficial to help adolescents develop selfcompassion skills (Neff \& McGehee, 2010).

\section{Objectives}

(1) Examine the impact of early memories of warmth and safeness on quality of atta chment in acdolescents;

(2) Explore the relationship between early positive memories, selfcompassion and psychopathology (depressive, anxiety and stres symptoms);

(3) Explore the relative contribution of emotional memories and selfcompassion in the prediction of depressive and anxiety symptoms.

\section{Method}

Panticipants and Procedures

The sample is composed by 651 adolescents, which 330 are boys $(50.7 \%)$ and 321 are girls $(49.3 \%)$, from $7^{\text {th }}$ to $12^{\text {th }}$ grader (years of education mean $=9.89$, $\mathrm{SD}=1.64)$. The mean a ge was 15.89 (SD $=1.99$ ) years old, ranging from 12 to 19. No gender differences were found concerning age, $t_{\langle 649\rangle}=1.19, p=.236$, and years of education, $t_{i 649\}}=-1.37, p=$ .17

This adolescents sample was collected from public schools in the district of Castelo Branco, Portugal. Ethics approval was granted by the Head Teacher of the school and parents were informed about the goals of the research and gave their consent. Adolescents were informed about the purpose of the study, aspects of confidentiality and consent.

\section{Measures}

Early Memories of Warmth and Safeness Scale for Adolescents (EMWSSA; Richter, Gilbert, \& McEwan, 2009; Portuguese version by Cunha, Xavier, Martinho, \& Matos, 2013) is a self-report questionnaire that mea sures recall of feeling warm, safe and cared for in childhood, i.e., early positive memories of warmth and affect. This is a 27-item scale and is rated on a 5 . point scale. On the original version, Richter and colleagues (2009) found
high Cranbach's al pha of .97. In this study the Cronbach's alpha was .95 .

Self-Compassion Scale (SCS; Neff, 2003; Portuguese version fo adolescents by Pintro-Gouveia, Cunha, Xavier, \& Castillio, 2011) composed by 26 items which assess six dimensions of self-compassion: SelfKindness; Self-Judgment; Common Humanity; Isolation; Mindfulness; and Over-Identification. Responses on the SCS are given on a 5 -point scale, with higher scores representing greater self-compassion. In this study only total of self-compassion was used. The Cronbacti's al pha was .87 for total scale.

Attachment Questionnaire for Children (AQ-C; Sharpe et al, 1998 Portuguese version by Cunha, Pinto-Gouveia, \& Xavier, 2011) is a simplified version of Hazen and Shaver's (1987) attachment measure. This questionnaire is composed by three stalementis describing characteristic behaviours and affects in relationships. Each descriprion represents one of were instructed to choose the description that a pplied best to them.

Depression, Anxiety and Stress Scales (DASS-21; Lovibond \& Lovibond, 1995, Pais-Ribeiro, Honraco \& leal, 2004) is a self-report measur composed of 21 it ans and designed to aseess three dimensions of psychopathological symptoms: depression, anxiety and stress. In this study the Cronbact's al pha for subscales were .90 for depression, .86 for anxiety the Cronbacth's alp st f

\section{Results}

1. Study of Early Positive Memories and Attachment Styles

In this study we used the categorical choice of attachment style in the $A Q-C$ and we obtained three groups of attachment style, namely secure ( $n=$ 394), avoidant insecure $(n=155)$ and ambivalent insecure $(n=102)$. We conducted an analysis of variance (ANOVA) to compare these three groups ternis of early positive memories. This analysis yielded significant Herences in oaly postive

rable 1. Means, standard deviations and F-values for EMWSS and symptoms measure [DASS-21] with attachment styles as grouping variable

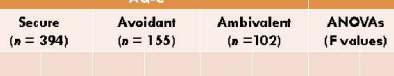
Post-hos
compariso $\begin{array}{llllllllll}\text { EMWWS } & 70.25 & 11.25 & 62.08 & 15.45 & 60.39 & 16.29 & 35.27 & .000 & \begin{array}{l}\text { Sec } \\ \text { Avys; } \\ \text { SA }\end{array}\end{array}$ Note. $A Q-C=$ Attachment Questionnaire for Children; EMWWSS-A = Early Memories of

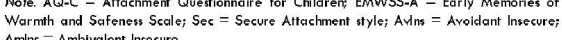

2. Correlations between early memories of warmth and safeness, self-compassion and psychopathology

As expectect, results show significant positive correlations between ectly memories of warmth and safeness and self-compassion. There are significant negative correlations between positive emotional memories and psychopathological symptoms (depression, anxiety and stress symptoms). Table 2. Correlations (two-tailed Pearson's $r$ ) between Early Memories of Warmth and
Safenesss Scale for Adolesscents (EMWSSS-A), Self-c-compassion (SCS) and depression, anxiely and stress subscales (DASS-21) $(N=651$ )

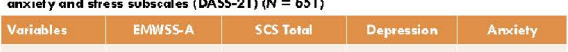

SCS Toral $\quad .41^{\text {matwat }}$

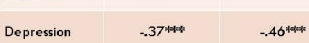

\begin{tabular}{|c|c|c|c|}
\hline Anxiery & $-20^{\text {wown }}$ & $-33^{\text {ondent }}$ & . 77 water \\
\hline
\end{tabular}

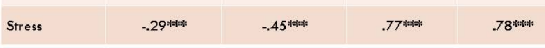

Note. **t; $<.001$. EMWSS-A = Early Memories of Warmth and Safeness Scale for
Adolescents; SCS $=$ Self-Compassion Toral; DASS-21 $=$ Depression, Anxiety and Stress Adoles

3. Predictors of depression and anxiety symptoms

Two linear regression analysis were performed, using positive emotional memories (measured by EMWSSS-A) and self-compassion (measured by SCS) to predict depression and anxiety symptoms (measured by DASS-21)

In the first analysis, positive emotional memories and self-compassion variables produced a significant model in the prediction of depression symptoms, $F_{(2,0+\Delta 8)}=109.385, p \leq .001$, and accounted for $25.2 \%$ of the variance in depression. Self-compassion emerged as the best global
predictor $(\beta=.36, p \leq .001)$, followed by positive emotional memories ( $\beta$ $=-.22, p \leq .001)$.

In the second regression analysis a statistically significart model was In the second regression analysis a stanisically significant model was symptoms and accounted for $12.9 \%$ of anxiety variance. The best predictors are self-compassion $(\beta=-27, p \leq 001)$ and positive ene best predictors are self-compassion
memories $(\beta=. .15, p \leq .001)$.

Table 3. Regression Line ar Analysis Summ ary for Depression and Anxiety (DASS-21)

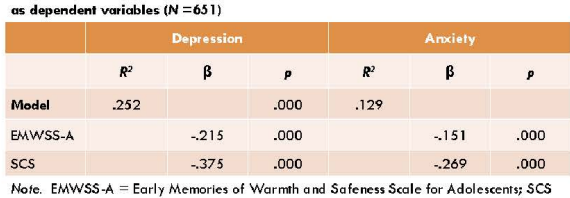
Note. EMWWSS-A A Early Memories of Warmth and Safeness Scale for Adolescents; SCS

\section{Diseussion}

-Adolescents classified with a secure attachment style showed significantly more early memories of warmth and safeness than those teenchgers with insecure attachment (ambivalent or a voidance).

"Additionally, positive emotional memories in chilchood revealed adequate discriminant validity for attachment style.

Early memories of warmth and safeness showed significant negative and moderate correlations with anxiety depressive and stress symptoms, and positive moderate association with self-compassion.

"Early positive memories and self-compassion have a significant and an independent contribution on the prediction of anxiety and clepressive symptoms in adolescent community.

\section{Conclusions}

The present study shows that the recall of emotional memories in childhood (e.g., feelings of warnth and safeness) is associated with self-compassion, as an emotian regulation process. So, these two variables may function as protective factors in the development of depressive and anxiety symptoms

\section{References}

Lovikond, P., \& Lovikond, H. (1995). The structure of negative emotiont states: Comparison of the Depression Anxiety Stress Scales (DASS) with
Beck Depressive and Anxiety Inventories. Behaviour Research and Therapy, 3, 335-343. $\mathrm{htpp} / / / \mathrm{dx}$.doi.org/10.1016/0005-7967(94)00075-U

Neff, K. (2003). Development and validation of a scale to measure selfcompassion. Self and identity, 2, 223-250.

Neff, K., \& McGehee, P. (2010). Self-compassion and psychological resilience among adolescents and young adults. Self ond lidentity, $q(3), 225$ 240. doi: $10.1080 / 15298660902979307$

Neff, K., Kirkpatrick, K.L., \& Rude, S.S. (2007). Self-compassion and adaptive psychological functioning. Joumal of Research in Personality, 47

Richtrer, A., Gilbert, P., \& MeEwan, K. (2009). Development of an early memories of warmth and safeness scale and its relationship to

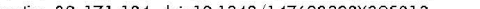

Sharpe, T. M., Killen, J. D., Bryson, S. W., Shisslak, C. M., Estes, L. S., Gray, Sharpe, T. M., Killen, J. D., Bryson, S. W., Shisslak, C. M., Estes, L. S., Gray,
N., Crago, M., \& Taylo, C. B. (1998). Aftachment style and weight concerns in Disorders, 23, 39-44.

Correspondence to: Marina Cunha, Instituto Superior Miguel Torga, Largo da Cruz de Celas, 1, 3000-132 Coimbra, Portugal 